\title{
Maintenance of the Austenite/Ferrite Ratio Balance in GTAW DSS Joints Through Process Parameters Optimization
}

\author{
Bryan R. Rodriguez ${ }^{1}(\mathbb{D})$, Argelia Miranda ${ }^{1, *(\mathbb{D})}$, David Gonzalez ${ }^{2}$, Rolando Praga ${ }^{2}(\mathbb{1})$ and \\ Eduardo Hurtado ${ }^{1}$ \\ 1 Corporacion Mexicana de Investigacion en Materiales S.A. de C.V., Ciencia y Tecnologia No. 790, Saltillo 400, \\ 25290 Saltillo, Coahuila, Mexico; brrv92@gmail.com (B.R.R.); eduardohd@comimsa.com (E.H.) \\ 2 Universidad Autonoma de Coahuila, Facultad de Sistemas, Ciudad Universitaria, Carretera a Mexico Km 13, \\ 25380 Arteaga, Coah., Mexico; davidgonzalez@comimsa.com (D.G.); rolandopraga@comimsa.com (R.P.) \\ * Correspondence: argelia.miranda@comimsa.com; Tel.: +52-844-411-3200
}

Received: 28 December 2019; Accepted: 3 February 2020; Published: 8 February 2020

check for updates

Abstract: The present work describes the influence of the parameters employed in the gas tungsten arc welding process (GTAW) when nickel powder is used as a filler metal in 2304/2507 duplex stainless-steel dissimilar joints. Multi-objective optimization was applied in order to maintain the austenite/ferrite percentage in the welded zone. A microstructural and phase quantification analysis was performed in each sample through optical and scanning electron microscopes. It was found that a nickel powder addition combined with low heat input increased the biphasic ratio across the different zones of the dissimilar welded samples. Although the austenite volume fraction increased in the 2304 heat-affected zone (HAZ) near to $25 \%$, it was not sufficient according to international standards. The obtained results led to the maintenance of the 50/50 phase percentage in the $2507 \mathrm{HAZ}$ welded joint side, as well as to the increment of the austenite percentage in the $2304 \mathrm{HAZ}$.

Keywords: duplex stainless steel; GTAW process; multi-objective optimization; dissimilar joints.

\section{Introduction}

Duplex stainless steel (DSS) derives its name from the stable microstructure at room temperature, which consists of approximately $50 \%$ austenite phase $(\gamma)$ and $50 \%$ ferrite phase $(\delta)$. This microstructure has a favorable combination of mechanical and anticorrosive properties, ensuring high levels of high-temperature resistance, optimum toughness, and ductility [1-4].

The welding processes used to join this type of material promote variations to the dual percentage of ferrite-austenite, because the microstructural heterogeneity generated by the thermal gradients can locally generate microstructural changes, influencing the mechanical behavior of the joint [3-6]. Controlling this dual percentage is of great importance to the maintenance of the mechanical properties, especially of the corrosion resistance. Therefore, different studies have been highly focused on supplemental elements or materials during the welding procedure. In a study conducted by Varbai and Májilinger in 2019, a method to measure the austenite/ferrite (A/F) ratio in the different zones of the welded sample through the analysis of its images using a proper etching attack was studied. Putz et al., in 2019, also studied this topic, focusing on the difference among various methods to measure the $\mathrm{A} / \mathrm{F}$ ratio on the welds correctly $[7,8]$.

In fusion welding processes of duplex stainless steels, the resultant microstructure in the temperature range to which the material is exposed solidifies as fully ferritic, and for austenite, the transformation cooling rate and the composition are both significant. In multi-pass welding at high 
temperatures, another phenomenon is observed: ferrite decomposition occurs, causing the formation of harmful secondary phases, such as sigma $(\sigma)$, chi $(\chi)$, carbides, and nitrides phases, which subsequently deteriorate the mechanical and corrosion-resistance properties of the DSS. Santos et al. conducted a study, based on the analysis of thermal history, which showed the temperature measured across the weld and its effect on the microstructural and mechanical behavior, and compared the results with the three-dimensional finite element model built. In addition, Sarlak, Atapour, and collaborators specifically studied the corrosion behavior across the welding in samples obtained by the welding process of a lean duplex stainless steel (LDSS) and its effect on the microstructure [9-11].

Various joining techniques, such as plasma, laser, tungsten inert gas (TIG), and gas metal arc welding (GMAW) are being developed to meet the requirements demanded by these materials, avoiding distortion. However, ferritization is a problem with these processes. In addition, the effect generated by the entry of heat into these materials is a research topic. Plasma arc welding has beneficial results for DSS, which is situated at a controlled heat input and an acceptable ferrite ratio compared with other processes. Flux-cored arc welding (FCAW) has gradually attracted strong attention in welding DSS due to its higher welding efficiency compared with the gas tungsten arc welding process (GTAW) process. However, studies on the microstructure, mechanical properties, and corrosion resistance of the DSS FCAW joint are limited. Advanced laser hybrid welding has a great advantage for DSS, because it reduces heat input and distortion level compared with SAW and FCAW [12,13]. The GTAW is a welding procedure that has been employed efficiently in past years to weld materials such as stainless steels due to its facility to produce sound joints that meet specific requirements of industries, added to its facility to work when thin materials are required. However, it has been observed that when the main welding parameters and conditions are not well controlled (welding current, welding speed, shielding gas, etc.), the mechanical and corrosive properties could be reduced. An example of this appears in the heat-affected zone (HAZ) and the fusion zone (FZ), where the microstructure undergoes rapid cooling and heating cycles that result in changes in the orientation and size of the ferritic grain, as well as in excessive amount of ferrite. Previous research reported that austenite contents of less than $30 \%$ are inadequate for most industrial applications [14-17]. Ravisankar et.al. studied the influence of welding speed and power on residual stress during the GTAW process of thin sections with constant heat input: the analysis of the heat source fitting revealed that the heat input of $300 \mathrm{~J} / \mathrm{mm}$ resulted in a proper weld penetration and HAZ. Chen et.al. analyzed the influence of cooling rates on microstructure evolution and pitting corrosion in the simulated heat-affected zone of 2304 LDSS and found that with resistance in the simulated HAZ of 2304 LDSS, the ferrite phase content increased gradually as the cooling rate increased [18,19].

The constant development of various applications employing duplex stainless steels used in the chemical, petrochemical, nuclear, and energy industries, among others, demands the adaptation of materials that meet the required service conditions, thus, promoting the development of hybrid structures with dissimilar metals (i.e., welding between stainless steels) and combining their respective advantages. However, dissimilar metal welding is often accompanied by a series of problems, such as secondary phase formation, and the distribution of dissimilar metal weld in the fusion zone, which must be controlled [3,20].

Various experiment design techniques (DoE) are currently employed in a variety of applications, with the purpose of identifying parameters associated with a process and determining its optimal configuration to improve process capabilities and performance. One of the most employed DoE techniques is the full factorial design, where the variables' effect is analyzed for a certain response. The determination of a correct selection by a trial and error method for each study is time-consuming and increases experimental cost; consequently, prediction models are gaining attention because they are employed to enhance parameters through the development of optimizing techniques. In the case of parameters with some randomness, e.g., a manual welding process, a prediction model, such as the general mixed linear model, is proposed [21,22]. When joining materials of similar or 
variant compositions, the main problem is the selection of welding parameter ranges to obtain the desired properties.

The aim of this investigation is to determine the optimal parameters of the GTAW process that allow an equitable proportion of phases in the microstructure of dissimilar joints to be obtained through multi-objective optimization, considering the employment of variables such as welding current and nickel powder addition.

\section{Materials and Methods}

\subsection{Materials}

UNS 2304 lean duplex stainless steel (LDSS) and UNS 2507 super duplex stainless steel (SDSS) were the base metals (BM) used in this study, with their composition (wt \%) shown in Table 1 . The base metals were shaped to sizes of $70 \times 60 \times 3 \mathrm{~mm}$ for LDSS and $70 \times 60 \times 2 \mathrm{~mm}$ for SDSS.

Table 1. Chemical composition of the base metals (wt \%): lean duplex stainless steel (LDSS); super duplex stainless steel (SDSS).

\begin{tabular}{cccccccccccccc}
\hline & $\mathbf{C}$ & $\mathbf{S i}$ & $\mathbf{C u}$ & $\mathbf{M n}$ & $\mathbf{M o}$ & $\mathbf{C r}$ & $\mathbf{N i}$ & $\mathbf{S}$ & $\mathbf{P}$ & $\mathbf{N}$ & $\mathbf{V}$ & $\mathbf{W}$ & $\mathbf{F e}$ \\
\hline LDSS 2304 & 0.02 & 0.48 & 0.29 & 1.37 & 0.36 & 23.5 & 5.02 & 0.014 & 0.031 & 0.10 & - & - & Bal. \\
SDSS 2507 & 0.018 & 0.13 & 0.17 & 0.85 & 3.86 & 25.2 & 6.72 & 0.001 & 0.03 & 0.27 & 0.026 & 0.09 & Bal. \\
\hline
\end{tabular}

Metallographic preparation of the samples was in accordance with standard ASTM E3-11. The samples were etched with modified Beraha's etch $\left(50 \mathrm{~mL} \mathrm{HCl}, 50 \mathrm{~mL} \mathrm{H}_{2} \mathrm{O}, 1 \mathrm{~g} \mathrm{~K}_{2} \mathrm{~S}_{2} \mathrm{O}_{5}\right.$, and $10 \mathrm{~g} \mathrm{NH}_{4}$ $\mathrm{F}-\mathrm{HF}$ ) for $12 \mathrm{~s}$ to reveal the microstructure in the LDSS 2304 side. On the other hand, for the welded zone and the SDSS 2507 side, Marble's etch $\left(10 \mathrm{~g} \mathrm{CuSO}_{4}, 50 \mathrm{~mL} \mathrm{HCl}\right.$, and $\left.50 \mathrm{~mL} \mathrm{H}_{2} \mathrm{O}\right)$ was used for $15 \mathrm{~s}$ in sequence.

Different characterization techniques were employed to analyze the microstructural behavior of the samples (optical and scanning electron microscopes), in addition to performing a punctual analysis by energy-dispersive X-ray spectroscopy (EDS) to study the A/F percentage in the $2304 \mathrm{HAZ \text {, }}$ the 2405-2507 FZ, and the 2507 HAZ of the welded joints.

\subsection{GTAW Process}

The welding procedure was developed employing a Miller Syncrowave 350 CC AC/DC Welder in a rolling direction, after cleaning with acetone to remove any contaminants such as grease and oil. The joint design was in butt configuration with the samples held on a work metal table with a $1.5 \mathrm{~mm}$ gap, where $1.5 \mathrm{~g}$ of nickel powder with spherical morphology and a diameter range of $150 \pm 60 \mu \mathrm{m}$ was added and impregnated with acetone (see the information in Table 2) as a filler metal before the welding procedure (Figure 1).

Table 2. Chemical composition of the nickel powder (wt \%).

\begin{tabular}{ccccccccccc}
\hline & $\mathbf{N i}$ & $\mathbf{C r}$ & $\mathbf{C u}$ & $\mathbf{S i}$ & $\mathbf{M g}$ & $\mathbf{F e}$ & $\mathbf{M n}$ & $\mathbf{A l}$ & $\mathbf{C}$ & $\mathbf{T i}$ \\
\hline Nickel powder & 91.73 & 5.28 & 0.005 & 0.56 & 0.002 & 1.04 & 0.008 & 0.036 & 0.22 & 0.015 \\
\hline
\end{tabular}




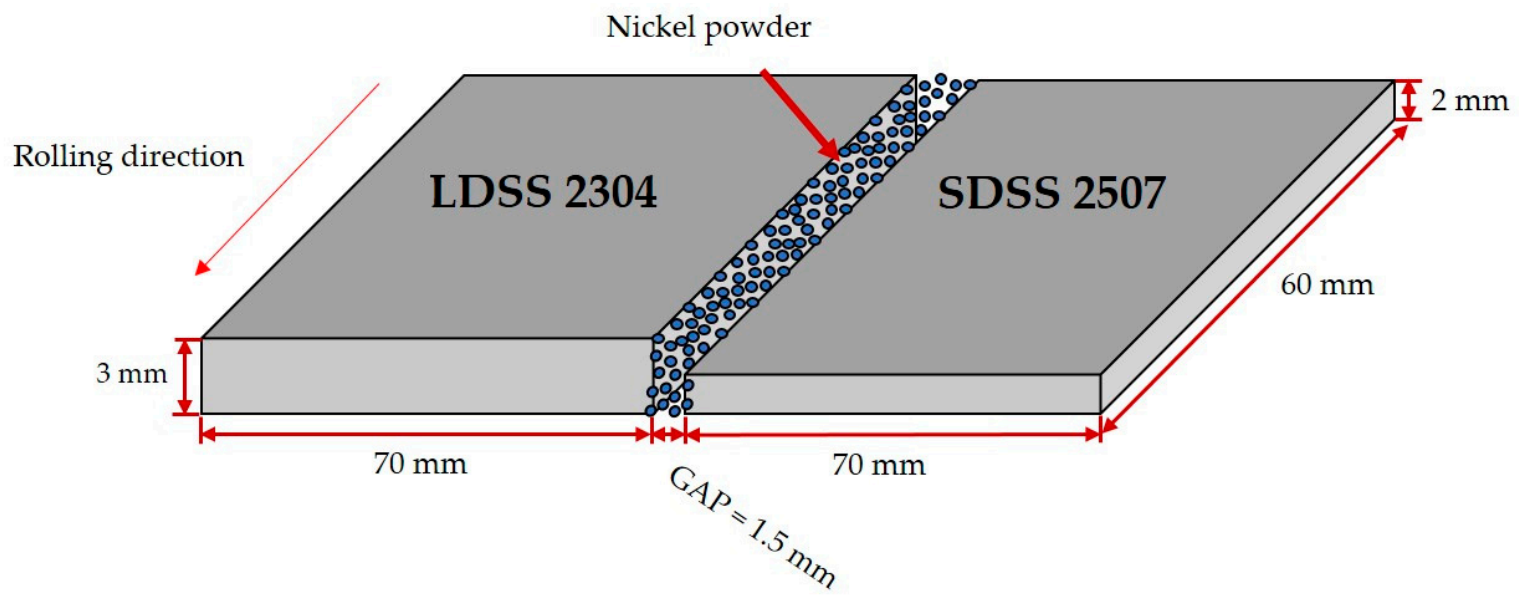

Figure 1. Scheme of the dissimilar duplex stainless-steel butt joint.

The welded joints were performed maintaining the parameters mentioned in Table 3 and were cooled at room temperature. A backing plate was not used in this case.

Table 3. Constant parameters of the gas tungsten arc welding (GTAW) manual process.

\begin{tabular}{|c|c|}
\hline \multicolumn{2}{|c|}{ Tungsten Electrode } \\
\hline Classification & EWTh-2 \\
\hline Diameter & $3.18 \mathrm{~mm}$ \\
\hline Angle & $60^{\circ}$ \\
\hline \multicolumn{2}{|c|}{ Welding Torch } \\
\hline Angle & $15^{\circ}$ (in relation to the vertical position) \\
\hline Arc length & $1.58 \mathrm{~mm}$ \\
\hline \multicolumn{2}{|c|}{ Welding } \\
\hline Direction & Push \\
\hline Position & Butt joint (plane) \\
\hline Current & DCEN $^{1}$ \\
\hline Shielding gas & $\operatorname{Ar}^{2}(15 \mathrm{~L} / \mathrm{min})$ \\
\hline
\end{tabular}

${ }^{1}$ Direct current with a negative charged electrode; ${ }^{2}$ Argon gas 5.0.

\subsection{Welding Parameters}

The initial tests were determinant on an experimental design based on a $2^{\mathrm{k}}$ arrange with two factors (current and nickel powder addition) with two levels, which generated four experiments to evaluate (Table 4). The aforementioned was in accordance with the determination of the influence of nickel addition as a filler metal and the welding current variation on the biphasic ratio across the different welding zones of the materials.

Table 4. Factorial design $2^{\mathrm{k}}$ (preliminary test).

\begin{tabular}{cccc}
\hline Test & Welding Current (A) & Nickel Powder Addition & Arc Voltage (V) \\
\hline 1 & 130 & Yes & 16.0 \\
2 & 130 & No & 16.0 \\
3 & 220 & Yes & 19.3 \\
4 & 220 & No & 19.3 \\
\hline
\end{tabular}

Table 5 presents the obtained results from the statistical analysis. It is important to highlight that both the nickel and the current possessed a significant effect in the austenite increment (value of 
$\mathrm{P}<0.05)$ in the weld zone and adjacent HAZ to the SDSS 2507. Nevertheless, the statistical results indicated that the previous interaction did not significantly influence the austenite percentage in the LDSS 2304 HAZ. Figure 2 schematizes the aforementioned, in accordance with the box graph of the austenite percentage.

Table 5. Statistical analysis results. HAZ: heat-affected zone.

\begin{tabular}{ccc}
\hline Zone & Parameter & P Value \\
\hline \multirow{2}{*}{ HAZ 2304 } & Ni powder & 0.961 \\
& Welding current (A) & 0.714 \\
HAZ 2507 & Ni powder & 0.020 \\
& Welding current (A) & 0.029 \\
Weld zone & Ni powder & 0.022 \\
& Welding current (A) & 0.025 \\
\hline
\end{tabular}

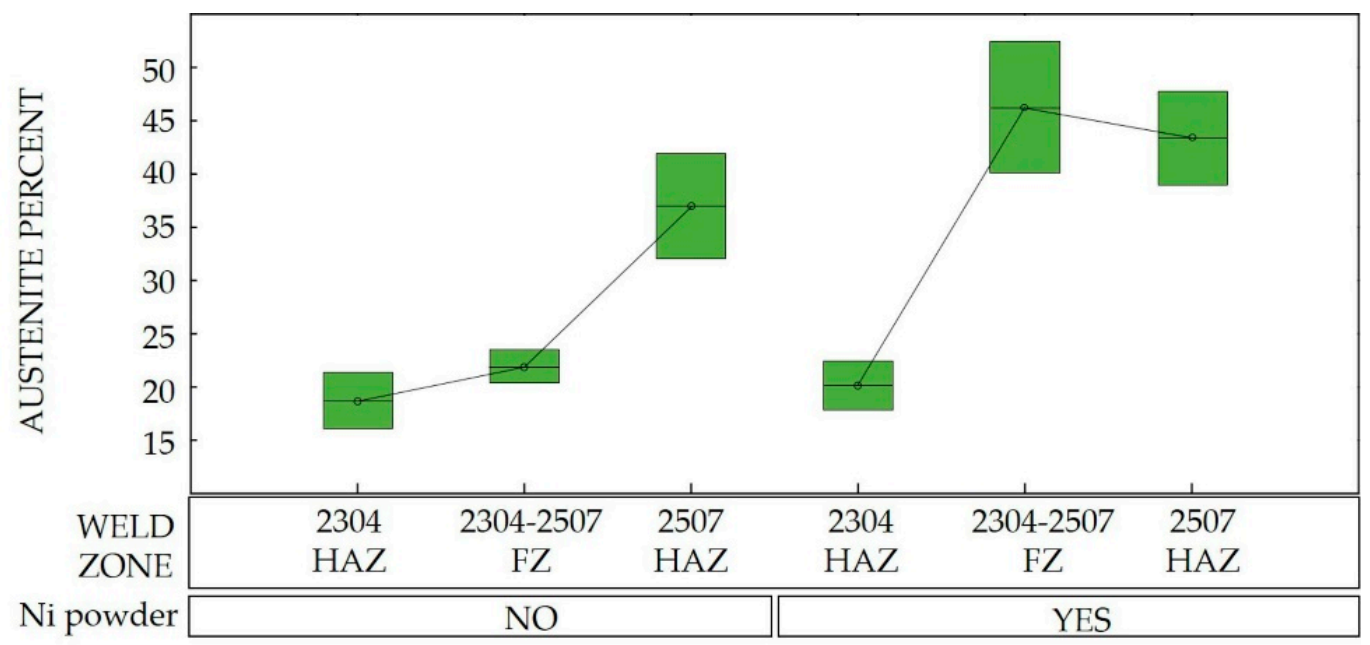

Figure 2. Box plot for austenite percentage. FZ: fusion zone; HAZ: heat-affected zone.

The above led the focus of the study to the random parameter, i.e., the welding speed, because the process is not automated and it is a function of the welder's ability.

In order to determine the effect of the welding speed, a $2^{\mathrm{k}}$ factorial design with central points was proposed in which the current welding values were considered. Nickel was also added to all the samples. Nevertheless, two central points were added, which are shown in Table 6.

Table 6. Factorial design $2^{\mathrm{k}}$ (welding parameters).

\begin{tabular}{cccc}
\hline Test & Welding Current (A) & Welding Speed $\left(\mathbf{m m ~ s}^{\mathbf{- 1}}\right)$ & Arc Voltage $(\mathbf{V})$ \\
\hline 5 & 220 & $3.9($ Low $)$ & 19.3 \\
6 & 220 & $5.0($ High) & 19.3 \\
7 & 175 & $3.0($ Low $)$ & 17.2 \\
8 & 175 & $3.4($ High) & 17.2 \\
9 & 130 & $2.8($ Low $)$ & 16.0 \\
10 & 130 & $3.6($ High) & 16.0 \\
\hline
\end{tabular}

The arc voltage was not contemplated in the experimental design; however, its values are presented in Table 6. The voltage was generated as a function of the established welding current in the equipment, because the welding equipment has a synergic control. 


\subsection{Optimization}

Analysis of the results of the above-mentioned testing determined the relation of the process parameters whilst maintaining the equitable proportion of austenite-ferrite in the welded regions. This led to the employment of a mixed-effect model, because regression models only contain error as a random element. However, different situations require models such as the mixed one, where more than one arbitrary term exists. These models are used to describe the relations between an output variable and a few co-variables grouped in accordance with one or more classification factors. This model employed the welding speed result as a non-controllable variable, i.e., it is identified as an arbitrary factor, such as the weld of these materials by the manual GTAW process. In this proposal, current and welding speed functions were used as input variables, respectively, which were correlated with the heat input.

The general mixed lineal model is given by

$$
Y=X \beta+Z v+\epsilon
$$

where $x$ is a dimension matrix of $N \times p$ known, $\beta$ is a $p \times 1$ vector of fixed parameters, $Z$ is an $N \times q$ matrix of constant known, $v$ is a $q \times 1$ vector of arbitrary effects, and $\varepsilon$ is an $N x 1$ vector of arbitrary errors. Assuming that

$$
{ }_{\varepsilon}^{\mathrm{v}} \sim \mathrm{N}\left\{\left(\begin{array}{l}
0 \\
0
\end{array}\right),\left[\begin{array}{cc}
\mathrm{G} & 0 \\
0 & \mathrm{R}
\end{array}\right]\right\}
$$

where $G$ and $R$ are known matrices that depend on an unknown parameter $\theta$ and considering that

$$
\operatorname{Var}(\mathrm{Y})=\mathrm{ZGZ}+\mathrm{R}
$$

models not only imply the $\beta$ parameters but also the variance of the $\theta$ parameters. Moreover, not only the hypothesis test of the $\beta$ can be observed, but also of the $\theta$ considering the expression [21-23].

$$
(\mathrm{Y}-\mathrm{X} \beta)^{\prime} \mathrm{V}_{\mathrm{Y}}{ }^{\wedge}(-1) *(\mathrm{Y}-\mathrm{X} \beta)
$$

Once the model that correlated the variables of the process was obtained, a multi-objective optimization supported by a genetic algorithm was developed to determine the values of the parameters that could maintain the austenite ratio percentage equitable in the weld zone and heat-affected zone of the SDSS 2507, increasing the HAZ adjacent to the LDSS 2304 (Table 7).

Table 7. Validation welding parameters.

\begin{tabular}{cccc}
\hline Test & Welding Current (A) & Welding Speed $\left(\mathbf{m m ~ s}^{-\mathbf{1}}\right)$ & Arc Voltage $(\mathrm{V})$ \\
\hline 11 & 133 & 2.7 & 16.8 \\
12 & 136 & 2.8 & 16.8 \\
\hline
\end{tabular}

\section{Results}

\subsection{Base Metal}

Figure 3 shows micrographs of the transversal phase of duplex stainless steel. It is possible to observe a ferritic matrix $(\delta)$ in dark color and austenite islands $(\gamma)$ dispersed across the matrix in light color in both micrographs. 


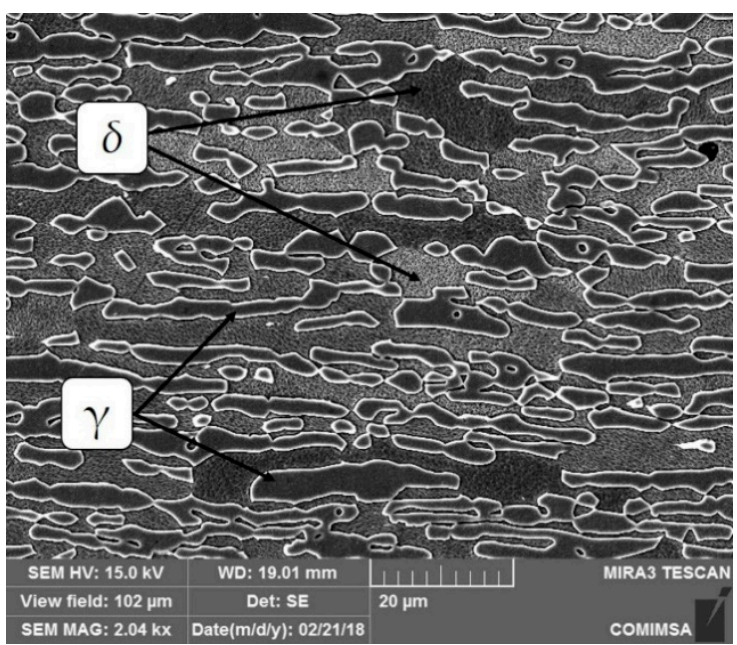

(a)

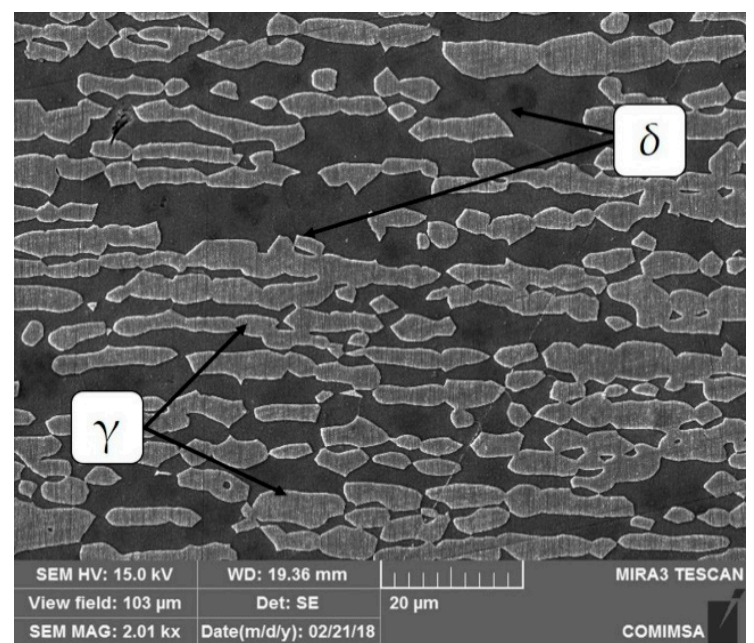

(b)

Figure 3. Base metal microstructure observed by scanning electron microscope (SEM): (a) SDSS 2304 and (b) SDSS 2507. $\delta$ : ferrite phase; $\gamma$ : austenite phase.

\subsection{Preliminary Tests}

Through microstructural analysis, it was observed that the joints with Ni powder presented islands with a high content of this element in the interface between the two metals below the fusion zone (Figure 4).

In accordance with the investigations, it was possible to observe different types of austenite produced by the subsequent transitions of the solid-state ferrite phase, which solidified through the melted metal: grain boundary austenite (GBA), Widmanstätten austenite (WA), intragranular austenite (IGA), and partially transformed austenite (PTA) [24] (Figures 5 and 6).

There was a significant difference in the A/F percentage both in preliminary and validation tests when varying the welding speed and $\mathrm{Ni}$ addition but not in the morphology of the current phases.

The area fraction of each phase of both duplex stainless steels through the distinct welded zones is presented in Figures 7 and 8. Nickel absence reduced considerably the austenite percentage in the FZ, while the welding current variation influenced the austenite fraction in the HAZ. The area fraction was directly proportional to the volume fraction. 

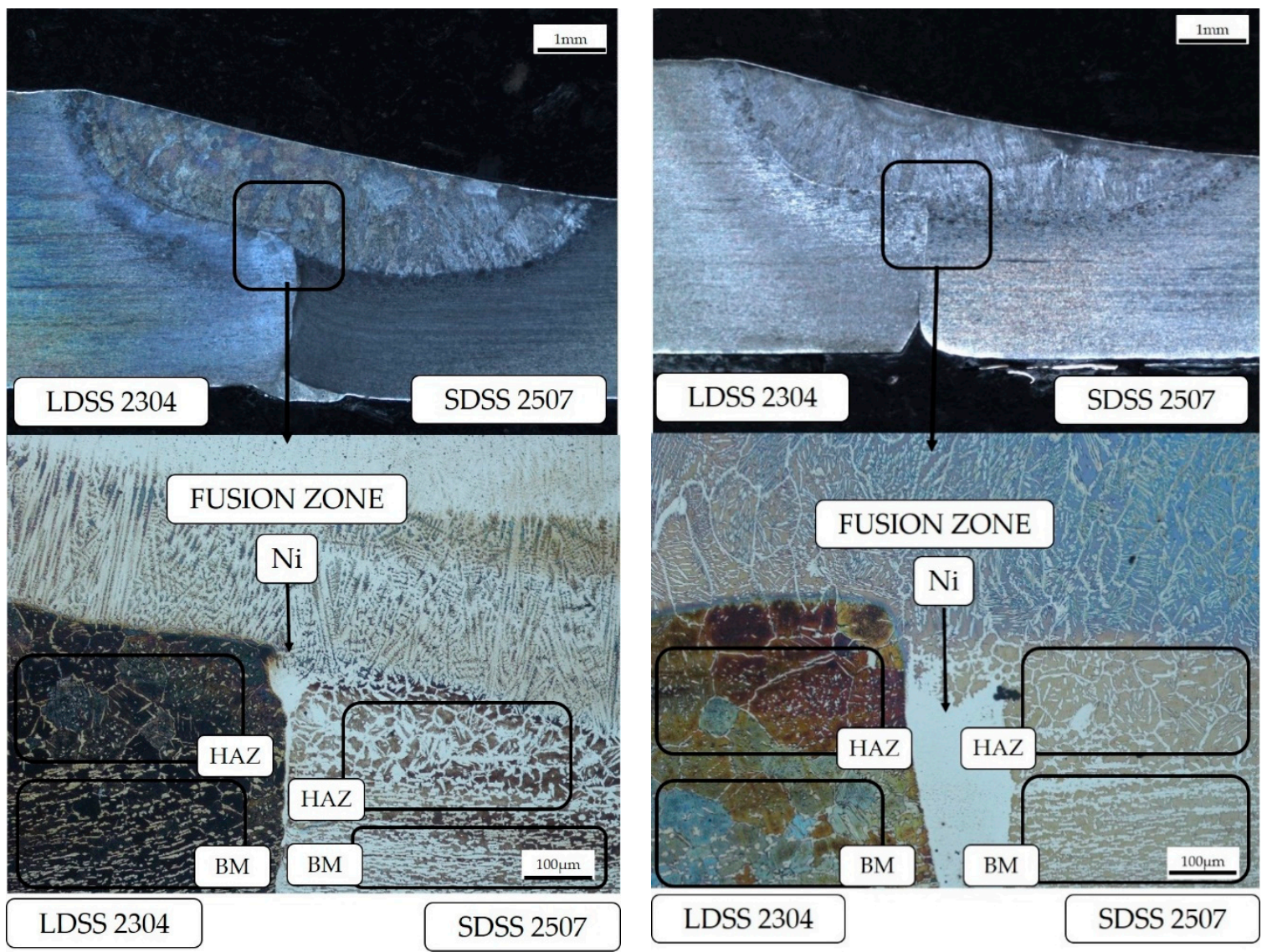

(a)

(b)

Figure 4. Welded zones by optical microscope to $10 \times$ : (a) Test \#3 and (b) Test \#1.

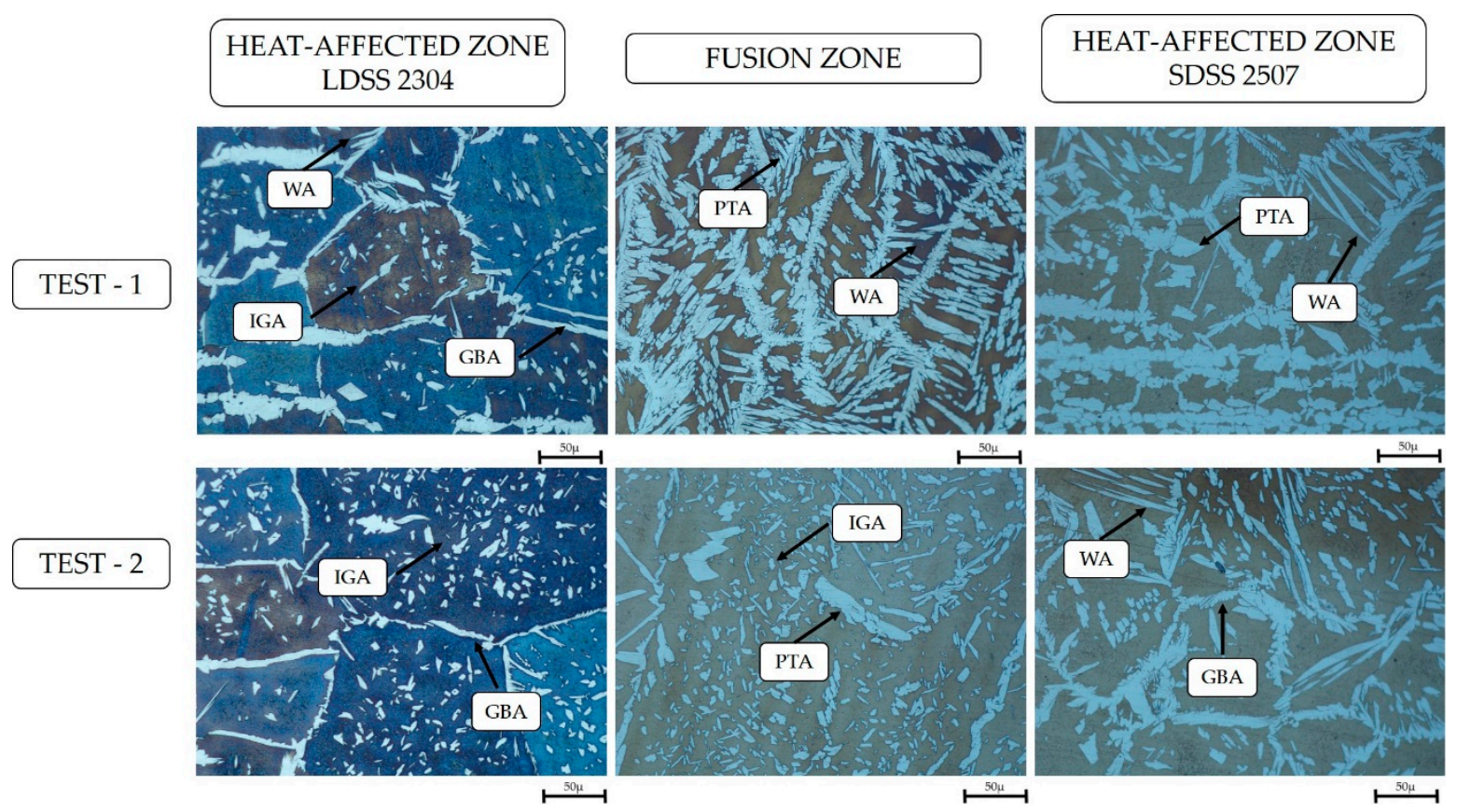

Figure 5. Welded zones by optical microscope to $50 \times$ : 130 A welding current. 


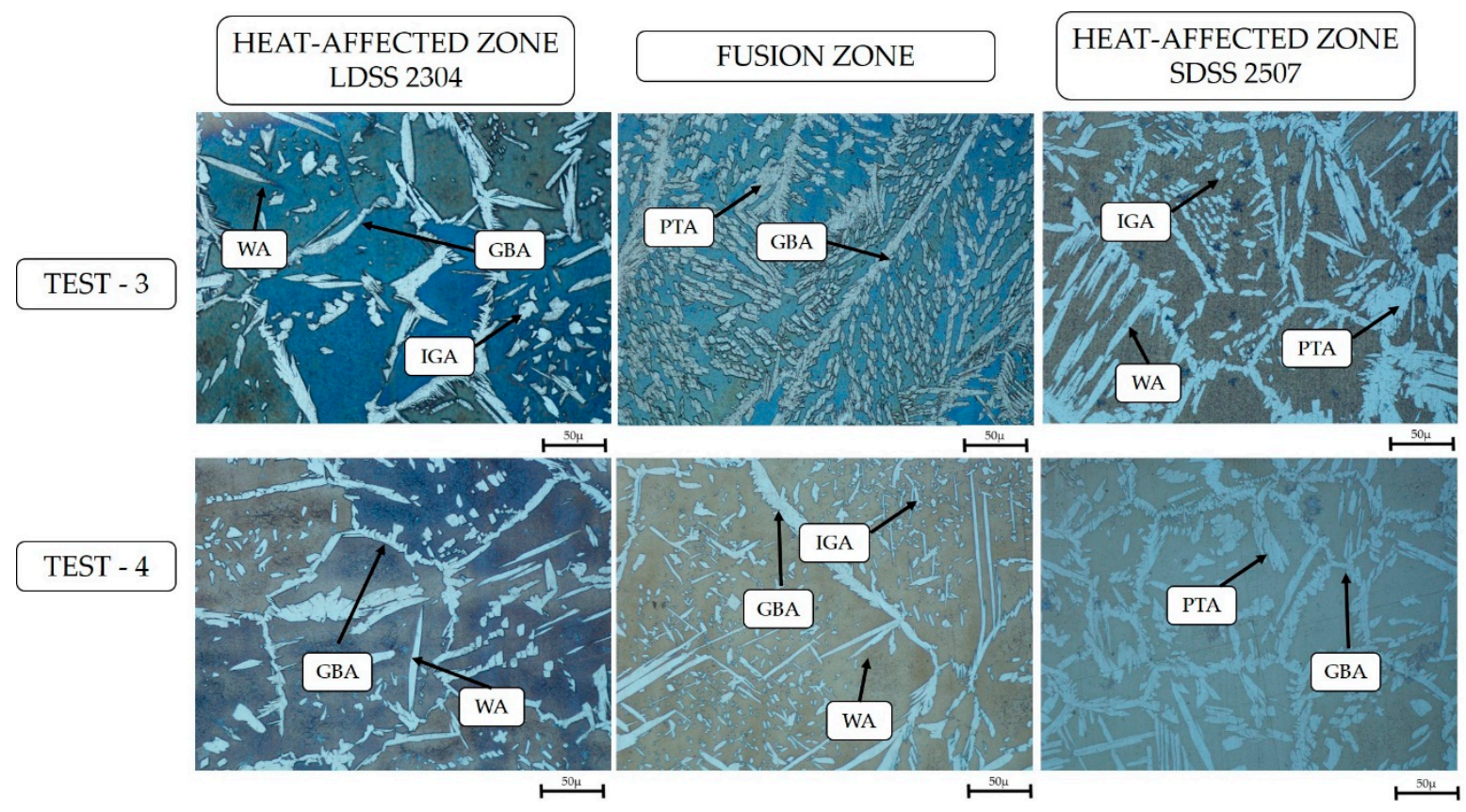

Figure 6. Welded zones by optical microscope to $50 \times$ : 220 A welding current.

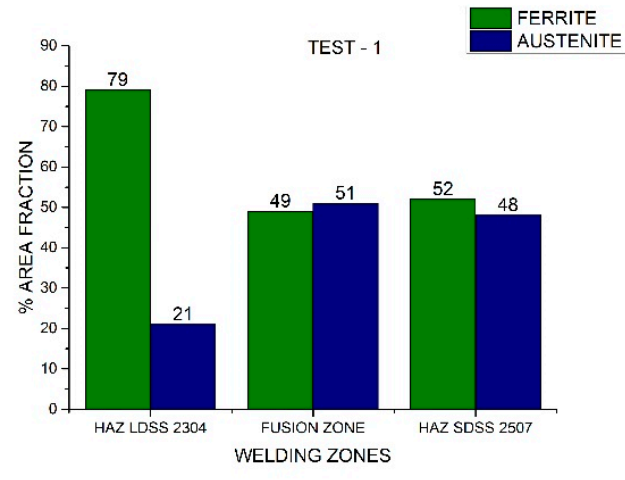

(a)

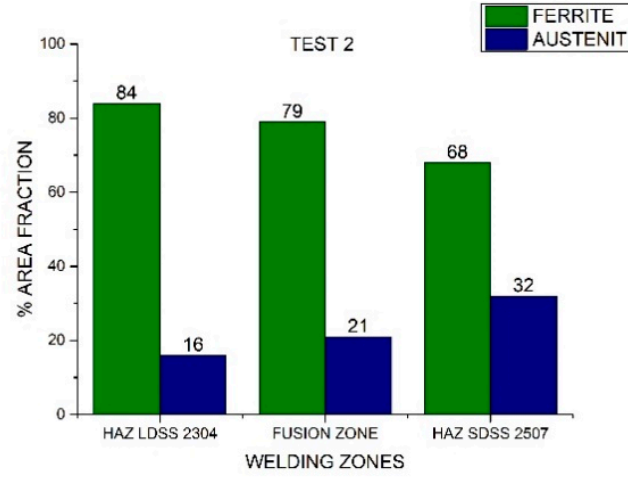

(b)

Figure 7. Area fraction through the distinct welded zones: (a) Test \#1 and (b) Test \#2.

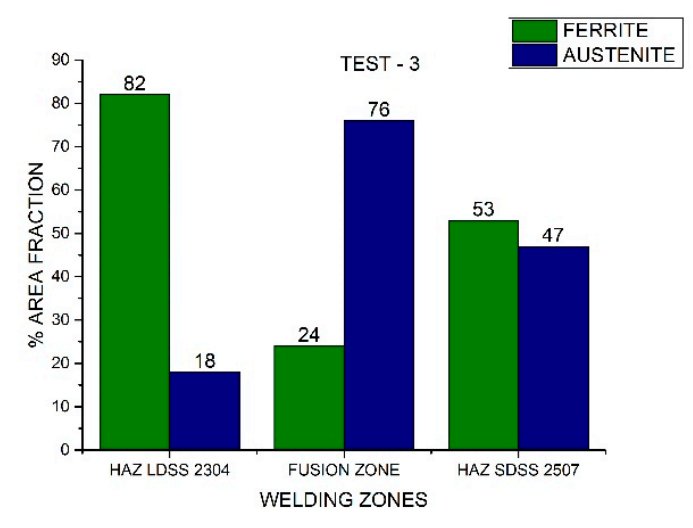

(a)

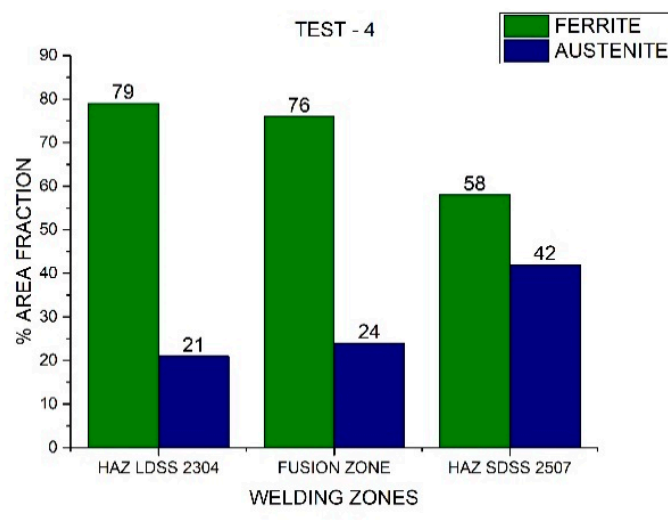

(b)

Figure 8. Area fraction through the distinct welded zones: (a) Test \#3 and (b) Test \#4. 


\subsection{Tests Joints}

\subsubsection{Microstructural Analysis and Phase Quantification}

The different types of primary austenite formed in the welded regions (Figure 9) were determined through an EDS analysis (Table 8).

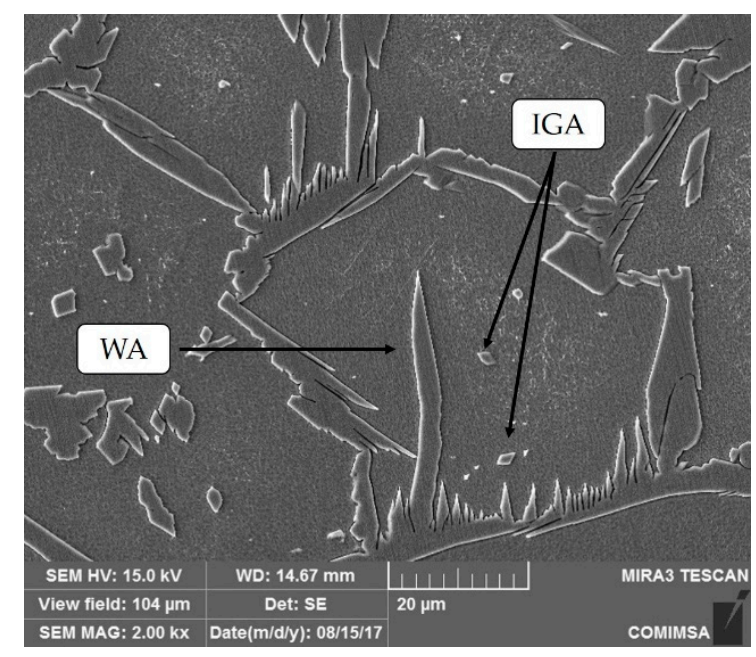

(a)

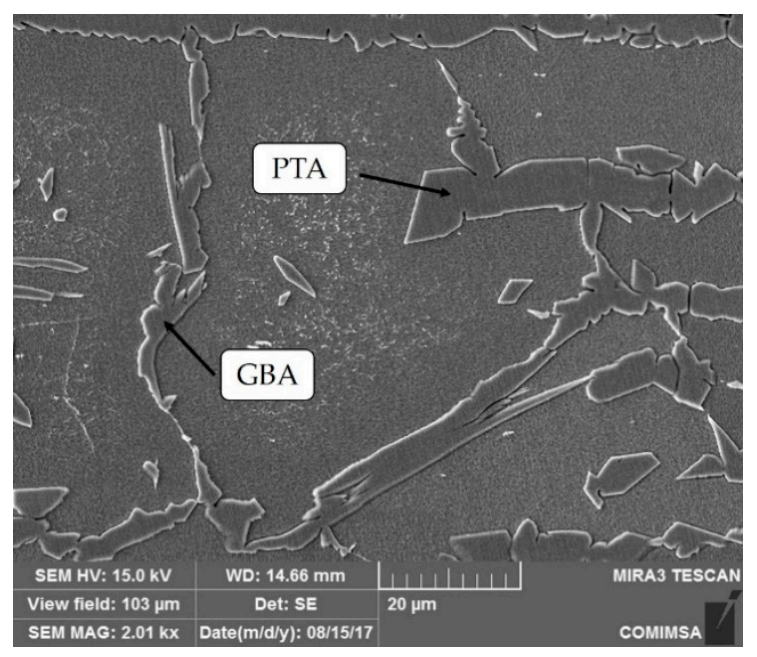

(b)

Figure 9. SEM micrographs of the heat-affected zone: (a) lean duplex stainless steel (LDSS) 2304; and (b) SDSS 2507. WA: Widmanstätten austenite; IGA: intragranular austenite; PTA: partially transformed austenite; GBA: grain boundary austenite.

Table 8. EDS analysis (wt. \%) of the phase proportions in the heat-affected zone.

\begin{tabular}{ccccccc}
\hline \multirow{2}{*}{ Phase } & \multicolumn{3}{c}{ LDSS 2304 } & \multicolumn{3}{c}{ SDSS 2507 } \\
\cline { 2 - 7 } & $\mathbf{C r}$ & Mo & Ni & Cr & Mo & Ni \\
\hline GBA & 23.18 & 1.26 & 3.80 & 25.09 & 3.09 & 6.55 \\
WA & 21.17 & 1.16 & 4.11 & 24.01 & 3.05 & 6.89 \\
IGA & 20.02 & 0.91 & 4.99 & 23.03 & 2.01 & 7.37 \\
PTA & 22.39 & 1.28 & 3.99 & 23.97 & 3.59 & 6.02 \\
\hline
\end{tabular}

In Figure 10, Figure 11, and Figure 12, the area fraction of each phase in both stainless steels across the distinct welded zones was observed.

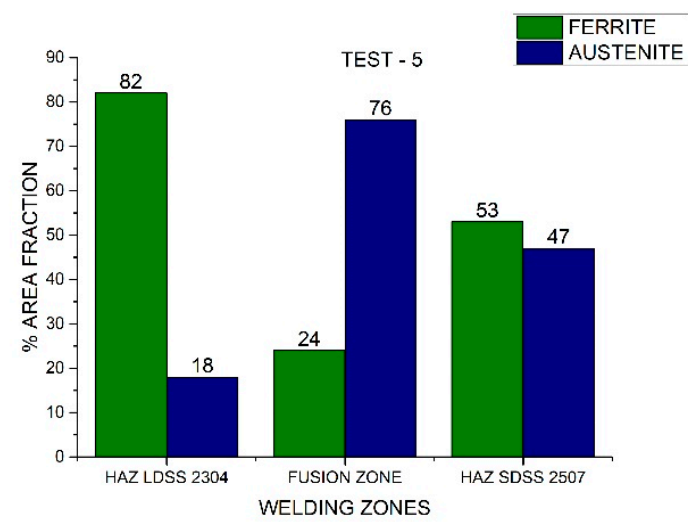

(a)

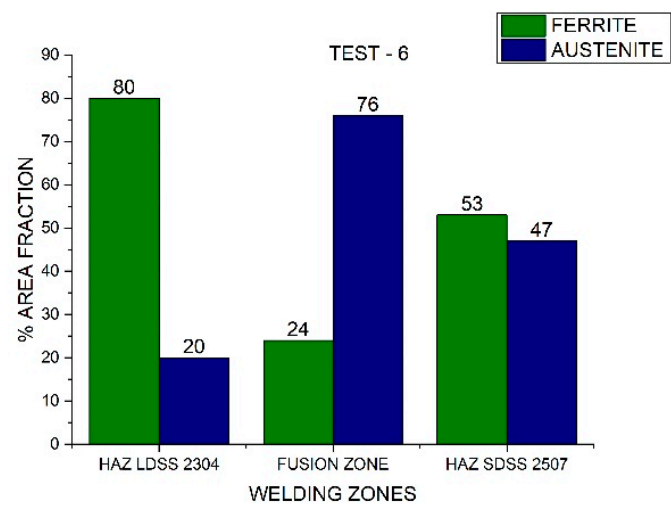

(b)

Figure 10. Area fraction through the distinct welded zones to 220 A: (a) Test \#5 and (b) Test \#6. 


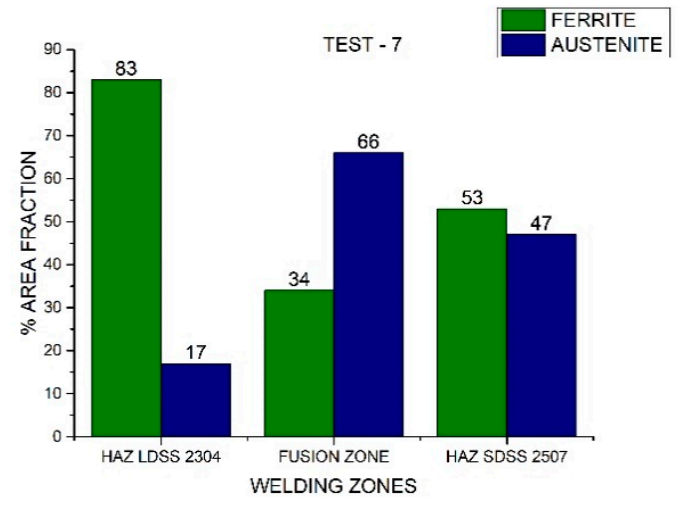

(a)

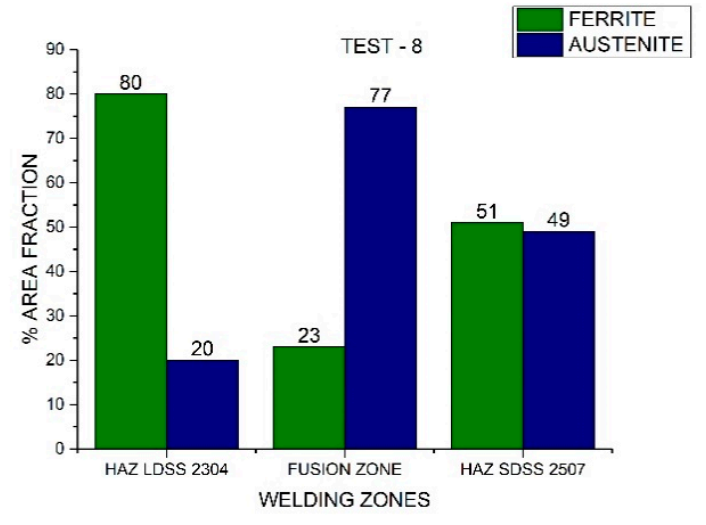

(b)

Figure 11. Area fraction through the distinct welded zones to 175 A: (a) Test \#7 and (b) Test \#8.

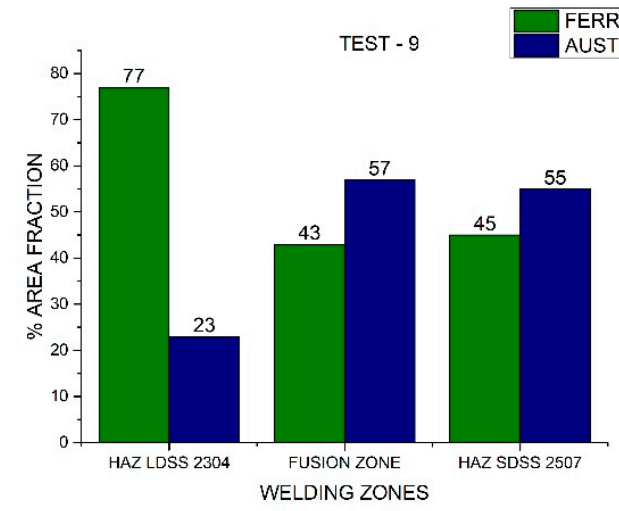

(a)

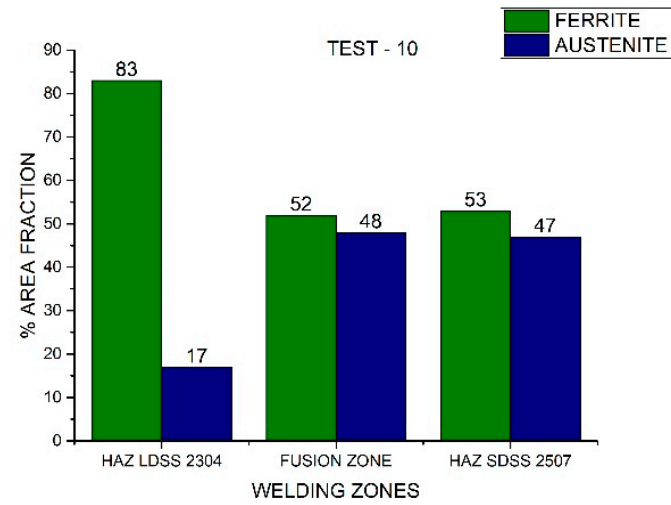

(b)

Figure 12. Area fraction through the distinct welded zones to 130 A: (a) Test \#9 and (b) Test \#10.

\subsubsection{Validation}

The experimental percentage measurement of the phases in the joint matched with the information provided by the general mixed lineal model and allowed for the establishment of the process parameters, which could maintain the phase duality in the HAZ of the SDSS 2507 and the welded zone. Meanwhile, in the LDSS 2304, HAZ values near $23 \%$ of the area fraction of the austenite were shown (Figure 13).

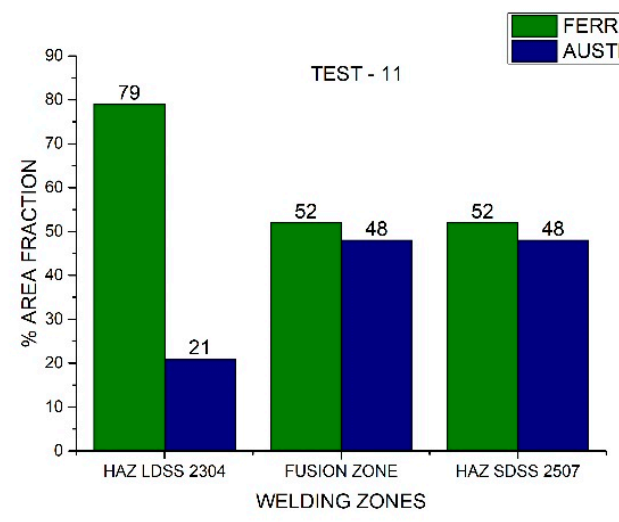

(a)

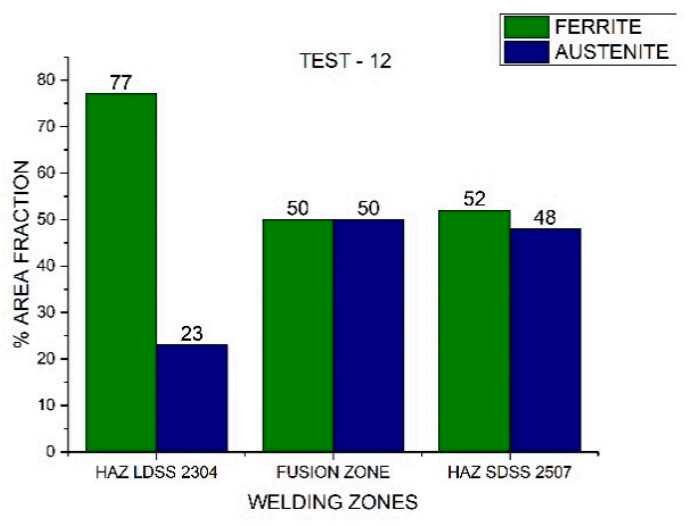

(b)

Figure 13. Area fraction through the distinct welded zones: (a) Test \#11 and (b) Test \#12. 
The highest content value of austenite in the FZs and HAZs in both steels was obtained by employing a welding current of 136A and an advancing speed of $2.89 \mathrm{~mm} \mathrm{~s}^{-1}$.

\section{Discussion}

The initial analysis of the joint showed that the high nickel concentration in the interface of the DSS employing a welding current of $130 \mathrm{~A}$ was a result of the lack of heat in the mentioned zone (Figure 4), preventing the diffusion of this element through the joint. Additionally, the microstructural study revealed the formation of four different types of primary austenite in the HAZ and FZ of both steels (Figures 5 and 6): grain boundary austenite (GBA), Widmanstätten austenite (WA), intragranular austenite (IGA), and partially transformed austenite (PTA) [13,24].

The effect of the filler metal was observed in Figures 5 and 6, highlighting the considerable increase of the austenite as well as its coarsening in the welded zone. Furthermore, the high quantity of alloying elements that constitute the duplex stainless steel and the cooling rate allowed for the stabilization of the austenite phase during the solid-state transformation (Figure 4). The analysis through EDS (Table 8) revealed that the content of elements of the IGA was due to its precipitation in poor $\mathrm{Cr}$ and Mo zones and rich Ni regions, as the WA maintained minor quantities of $\mathrm{Cr}, \mathrm{Mo}$, and $\mathrm{Ni}$, because its formation came later than the GBA growth (Figure 9) $[13,25]$.

The different phase quantifications employing the process parameters generated by the design of experiments demonstrated that the microstructure depended on the thermal cycle of the welding procedure (Figures 7 and 8). Different studies conducted have demonstrated that in DSS, the heat input influences the final results (which can be determined by current and speed welding), because it predicts the cooling speed value: the lower the heat input, the greater the cooling speed. The low heat input generates a high cooling speed, leading to a microstructural imbalance and promoting the excessive content of ferrite [26]. The addition of alloying elements in the shielded atmosphere or as a filler metal (i.e., nickel powder) promoted the change from ferrite to austenite at high temperatures and the later stabilization of the phase at room temperature [27].

On the other hand, the austenite ferrite dual percentage remained in the SDSS 2507 HAZ employing $220 \mathrm{~A}$ and $175 \mathrm{~A}$ in both speeds, increasing considerably the austenite quantity in the FZ (Figures 10 and 11). In addition, when employing a current of $130 \mathrm{~A}$, the 50/50 percentage remained in the FZ and HAZ of the SDSS 2507 (Figure 12). Nevertheless, the percentage of the austenite was reduced considerably in the HAZ of the LDSS 2304, promoting values below $25 \%$. The optimization of the process parameters led to a welding current of $130 \mathrm{~A}$ and low welding speeds (Figure 13).

\section{Conclusions}

This article shows the research work carried out to analyze the influence of the GTAW process parameters on dissimilar joints of lean duplex stainless steel UNS S32404 and super duplex stainless steel UNS S32507. Based on the results provided through experimental development, the following can be concluded:

- The joints have an acceptable surface quality when using low welding current parameters (130 A) and a welding speed of $2.7 \mathrm{~mm} \mathrm{~s}^{-1}$.

- The autogenous GTAW process requires the amount of heat input and the cooling speed to be regulated through the welding speed and current, because a low heat input and a high cooling speed lead to an undesirable imbalance of ferrite/austenite proportion in dissimilar duplex stainless-steel joints, which affects the material properties negatively.

- The use of nickel powder as a filler metal in the GTAW process when welding duplex stainless steel favors the formation of higher content of the austenite phase in the welding zone.

- Different types of austenite (IGA, GBA, WA, and PTA) are formed in the microstructure of the joint due to the welding thermal gradients. Secondary austenite formation is not clearly identified, 
because the joint was not overheated because of the effect of multiple beads or subsequent heat treatments.

- These findings can be employed by welding engineers to improve the austenite/ferrite balance with nickel powder addition in the duplex stainless=steel dissimilar joints. Likely, the obtained parameters can be used as a reference.

Author Contributions: Conceptualization, B.R.R. and A.M.; Methodology, B.R.R.; Software, D.G. and R.P.; Validation, E.H., D.G., and R.P.; Formal Analysis, B.R.R.; Investigation, B.R.R.; Writing-Original Draft Preparation, B.R.R.; Writing - Review and Editing, A.M.; Supervision, A.M. and D.G. All authors have read and agreed to the published version of the manuscript.

Funding: This research was funded by CONACYT - México.

Acknowledgments: The authors thank Eng. Ramiro Rodríguez Rosales and MSc. Cindy E. Morales Bazaldúa for the suggestions and contributions to this research.

Conflicts of Interest: The authors declare no conflict of interest.

\section{References}

1. Yoon, H.; Ha, H.Y.; Kim, S.D.; Lee, T.H.; Jang, J.H.; Moon, J.; Kang, N. Effects of carbon substitution for nitrogen on the pitting corrosion resistance of type UNS S32205 duplex stainless steel. Corros. Sci. 2019, 108308. [CrossRef]

2. Lippold, D.J.; Kotecki, J.C. Welding Metallurgy and Weldability of Stainless Steels; John Wiley \& Sons, Inc.: Hoboken, NJ, USA, 2005.

3. Kangazian, J.; Shamanian, M. Mechanical and microstructural evaluation of SAF 2507 and incoloy 825 dissimilar welds. J. Manuf. Process. 2017, 26, 407-418. [CrossRef]

4. Bettahar, K.; Bouabdallah, M.; Badji, R.; Gaceb, M.; Kahloun, C.; Bacroix, B. Microstructure and mechanical behavior in dissimilar 13Cr / 2205 stainless steel welded pipes. Mater. Des. 2015, 85, 221-229. [CrossRef]

5. Yousefieh, M.; Shamanian, M.; Saatchi, A. Influence of Heat Input in Pulsed Current GTAW Process on Microstructure and Corrosion Resistance of Duplex Stainless Steel Welds. J. Iron Steel Res. Int. 2011, 18, 65-69. [CrossRef]

6. Yang, Y.; Yan, B.; Li, J.; Wang, J. The effect of large heat input on the microstructure and corrosion behaviour of simulated heat affected zone in 2205 duplex stainless steel. Corros. Sci. 2011, 53, 3756-3763. [CrossRef]

7. Varbai, B.; Májlinger, K. Optimal etching sequence for austenite to ferrite ratio evaluation of two lean duplex stainless steel weldments. Measurement 2019, 147, 106832. [CrossRef]

8. Putz, A.; Althuber, M.; Westin, E.M.; Willidal, T.; Enzinger, N. Methods for the measurement of ferrite content in multipass duplex stainless steel welds. Weld. World 2019, 1075-1086. [CrossRef]

9. Pérez, A.F.M.; Breda, M.; Calliari, I.; Medina, G.Y.P.; Sandström, R. Detrimental Cr-rich Phases Precipitation on SAF 2205 Duplex Stainless Steels Welds After Heat Treatment. Soldag. Inspeção 2016, 21, 165-171. [CrossRef]

10. Santos, T.F.A.; Idagawa, H.S.; Ramírez, A.J. Thermal history in UNS $\$ 32205$ duplex stainless steel friction stir welds Thermal history in UNS $S 32205$ duplex stainless steel friction stir welds. Sci. Technol. Weld. Join. 2014, 19, 150-156. [CrossRef]

11. Sarlak, H.; Atapour, M.; Esmailzadeh, M. Corrosion behavior of friction stir welded lean duplex stainless steel. Mater. Des. 2015, 66, 209-216. [CrossRef]

12. Tan, H.; Wang, Z.; Jiang, Y.; Yang, Y.; Deng, B.; Song, H.; Li, J. Influence of welding thermal cycles on microstructure and pitting corrosion resistance of 2304 duplex stainless steels. Corros. Sci. 2012, 55, 368-377. [CrossRef]

13. Zhang, Z.; Jing, H.; Xu, L.; Han, Y.; Zhao, L. Investigation on microstructure evolution and properties of duplex stainless steel joint multi-pass welded by using different methods. Mater. Des. 2016, 109, 670-685. [CrossRef]

14. Paulraj, P.; Garg, R. Effect of welding parameters on pitting behavior of GTAW of DSS and super DSS weldments. Eng. Sci. Technol. Int. J. 2016, 19, 1076-1083. [CrossRef] 
15. Zhang, Z.; Jing, H.; Xu, L.; Han, Y.; Zhao, L. Effects of nitrogen in shielding gas on microstructure evolution and localized corrosion behavior of duplex stainless steel welding joint. Appl. Surf. Sci. 2017, 404, 110-128. [CrossRef]

16. Zhou, Z.; Löthman, J. Dissimilar welding of super-duplex and super-austenitic stainless steels. Weld. World 2017, 61, 21-33. [CrossRef]

17. Hashemi, M.; Halvaee, A. Effect of GTAW Parameters on Structure and Mechanical Properties of C86300 Weld Joint. Trans. Indian Inst. Met. 2014, 67, 741-752. [CrossRef]

18. Ravisankar, A.; Velaga, S.K.; Rajput, G.; Venugopal, S. Influence of welding speed and power on residual stress during gas tungsten arc welding (GTAW) of thin sections with constant heat input: A study using numerical simulation and experimental validation. J. Manuf. Process. 2014, 16, 200-211. [CrossRef]

19. Chen, L.; Tan, H.; Wang, Z.; Li, J.; Jiang, Y. Influence of cooling rate on microstructure evolution and pitting corrosion resistance in the simulated heat-affected zone of 2304 duplex stainless steels. Corros. Sci. 2012, 58, 168-174. [CrossRef]

20. Jiang, Z.; Chen, X.; Yu, K.; Lei, Z.; Chen, Y.; Wu, S.; Li, Z. Improving fusion zone microstructure inhomogeneity in dissimilar-metal welding by laser welding with oscillation. Mater. Lett. 2019, 126995. [CrossRef]

21. Rodríguez-Cerda, F.I.; González-González, D.S.; Ojeda-Castañeda, R.B.; Praga-Alejo, R.J.; Flores-Díaz, J.A. Modelado y Optimización del Proceso de Soldadura Robótica GMAW a Unión Traslape Considerando una Covariable Aleatoria. In Proceedings of the 2nd Annual Registration Conference Mexican Manufacturing Renewable Energy, Nuevo, León, México, 19-20 May 2016.

22. González-González, D.S.; Praga-Alejo, R.J.; Ramírez-Méndez, E.; Gómez-Gaona, O.P.; Coronado, J.G. Modelo de efectos mixtos para la optimización del proceso de soldadura GMAW. Conv. Científica Ing. y Arquit. 2018, 19, 1-8.

23. Costa, P.S. Aplicación de las Transformaciones de Fase y Modelos Estadísticos en la Optimización del Proceso de Soldadura Por Arco Sumergido en Uniones de Acero API 51 X70; Corporación Mexicana de Investigación en Materiales S.A. de C.V.: Saltillo, Mexico, 2015.

24. Tahaei, A.; Pérez, A.F.M.; Merlin, M.; Valdés, F.A.R.; Garagnani, G.L. Effect of the Addition of Nickel Powder and Post Weld Heat Treatment on the Metallurgical and Mechanical Properties of the Welded UNS S32304 Duplex Stainless Steel. Soldag. Inspeção 2016, 21, 197-208. [CrossRef]

25. Ramkumar, K.D.; Bajpai, A.; Raghuvanshi, S.; Singh, A.; Chandrasekhar, A.; Arivarasu, M.; Arivazhagan, N. Investigations on structure-Property relationships of activated flux TIG weldments of super-duplex/austenitic stainless steels. Mater. Sci. Eng. 2015, 638, 60-68. [CrossRef]

26. Jiang, Y.; Tan, H.; Wang, Z.; Hong, J.; Jiang, L.; Li, J. Influence of Cr eq/Ni eq on pitting corrosion resistance and mechanical properties of UNS S32304 duplex stainless steel welded joints. Corros. Sci. 2013, 70, 252-259. [CrossRef]

27. Muthupandi, V.; Srinivasan, P.B.; Shankar, V.; Seshadri, S.K.; Sundaresan, S. Effect of nickel and nitrogen addition on the microstructure and mechanical properties of power beam processed duplex stainless steel (UNS 31803) weld metals. Mater. Lett. 2005, 59, 2305-2309. [CrossRef]

(C) 2020 by the authors. Licensee MDPI, Basel, Switzerland. This article is an open access article distributed under the terms and conditions of the Creative Commons Attribution (CC BY) license (http://creativecommons.org/licenses/by/4.0/). 